\title{
Relationship of Blood Pressure to Sodium and Potassium Excretion in Japanese Women
}

\author{
Koichi Takemori, Seiji Mikami, Susumu Nihira and \\ NaOSUKe SASAKI \\ Department of Hygiene, Hirosaki University School of \\ Medicine, Hirosaki 036
}

\begin{abstract}
Takemori, K., Mikami, S., Nihira, S. and Sasaki, N. Relationship of Blood Pressure to Sodium and Potassium Excretion in Japanese Women. Tohoku J. Exp. Med., 1989, 158 (4), 269-281 — The cross-sectional association of blood pressure with urinary sodium and potassium excretion was investigated with a stepwise regression analysis. Spot urine of 7441 females between 40 and 69 years was collected from 169 municipalities (88 urban and 81 rural) covering all prefectures in Japan. The filter paper sampling technique for urine was used to collect samples of subjects from March to December in 1985. Spot urine samples were analyzed for sodium, potassium and creatinine. In addition, 24-hr sodium and potassium excretions were estimated by predictive equations. Blood pressure, sodium excretion and sodium/potassium ratios were higher in rural areas than in urban areas. Consistent positive correlations between urinary sodium and blood pressure, and negative correlations between urinary potassium and blood pressure were observed in the whole country of Japan, in both urban and rural areas, and also in separate observations of twelve regions in Japan with some exceptions. When compared in standardized partial regression coefficients, relative effects of potassium on systolic blood pressure were higher than those of sodium in the whole of Japan, in urban and rural areas, and in five among the twelve regions. The present Japanese study confirmed a positive within-population relationship between sodium excretion and blood pressure and a negative relationship between potassium excretion and blood pressure. —— sodium ; potassium ; blood pressure; hypertension; epidemiology
\end{abstract}

Hypertension is an important risk factor for cardiovascular diseases, especially heart attacks and strokes. Mean sodium intake and blood pressure levels have been found to be correlated between populations (Gleibermann 1973; Simpson 1985), but correlations have been difficult to demonstrate within a population (Simpson 1985). Some within-population studies have reported sodium intake to be either inversely (McCarron et al. 1984) or not related to blood pressure (Karvonen and Punsar 1977; Walker et al. 1979; Schlierf et al. 1980 ;

Received June 27, 1989; revision accepted for publication July 25, 1989.

Offprint requests to : Assist. Prof. Koichi Takemori, Department of Hygiene, Hirosaki

University School of Medicine, Zaifu-cho 5, Hirosaki 036, Japan. 
Staessen et al. 1981 ; Kok et al. 1986), whereas, in Oriental population studies, sodium intake correlated positively with blood pressure (Kesteloot et al. 1980, 1987).

Both epidemiological observations (Walker et al. 1979 ; Kesteloot et al. 1980, 1987 ; Watson et al. 1980 ; Staessen et al. 1981 ; Khaw and Barrett-Connor 1984 ; Gruchow et al. 1985) and animal studies (Dahl et al. 1972) have suggested that a high dietary intake of potassium is associated with lower blood pressure. Some clinical trials have demonstrated lowering of blood pressure with potassium supplementation in both hypertensive (Iimura et al. 1981; MacGregor et al. 1982) and normotensive persons (Khaw and Thom 1982). Recently, Intersalt Cooperative Research Group (1988) showed that sodium excretion was positively correlated with blood pressure and potassium excretion was negatively associated with blood pressure of individual subject after adjustment for confounding variables.

Japanese consume a high salt diet and have the highest stroke rates. In some areas of northern Japan, the average salt intake was reported to be over 25 g daily (Sasaki 1962). There still remains regional variation of salt intake, though recently the level of intake has diminished (Ministry of Health and Welfare 1988).

We have developed the filter paper method (Takemori 1980) for sampling urine which has enabled the sampling of large numbers of subjects from distant places by mail. The purpose of the present study was to investigate the relationship of blood pressure to urinary sodium and potassium within a population. We used multivariate statistical techniques to analyze data obtained by nationwide sampling.

\section{Subjects and Methods}

Fifty filter paper strips $(2 \times 4.5 \mathrm{~cm}$, No. 6 ; Toyo Roshi Co., Ltd., Tokyo $)$, a collective schedule and an explanatory note of the survey were mailed to two urban and two rural municipalities in all the prefectures in Japan after receiving consent for the present survey. Filter paper strips soaked in spot urine and free volume samples from females between 40 and 69 years who participated in the general health examinations conducted by municipalities were collected from each of the fifty subjects. The strips were dried at room temperature and wrapped with aluminium foil. These samples were then mailed to the laboratory between March and December in 1985 and stored in a refrigerator at $5-10^{\circ} \mathrm{C}$ until measurement. Sodium $(\mathrm{Na})$, potassium $(\mathrm{K})$ and creatinine $(\mathrm{Cr})$ were extracted from the strips utilizing $15 \mathrm{ml}$ of blank solution (Takemori 1981) for flame photometry, at $25^{\circ} \mathrm{C}$ for one $\mathrm{hr}$. Sodium and potassium were measured using flame protometry and creatinine was measured by the Jaffe method. Twenty-four hour (one day's) urinary sodium and potassium excretions were estimated from the concentration of sodium, potassium and creatinine in the spot urine by the predictive equations of Kawasaki et al. $(1985,1986)$ for sodium and Hirata et al. (1985) for potassium. The predictive equations are cited in the footnote of Table 1.

The name of the municipality, the date and the time of day of survey, age, height, weight and blood pressure of the subjects were entered in the collective schedule. Other information such as a history of hypertension or medication for hypertension was not included. According to the diagnostic definition of cerebrovascular diseases by the Japanese Association for Cerebro-Cardiovascular Disease Control (1983), blood pressure was measured by public health nurses using standard mercury sphygmomanometers after sam- 
TABLE 1. Anthropometric data, blood pressure, estimated one day's urinary potassium and sodium excretion and sodium/potassium ratio in spot urine from middleaged female adults (40-69 years) in the whole of Japan, urban and rural areas

\begin{tabular}{|c|c|c|c|c|c|c|c|c|c|}
\hline & $\begin{array}{c}\text { Age } \\
\text { (years) }\end{array}$ & $\mathrm{N}$ & $\begin{array}{l}\text { Height } \\
\text { (cm) }\end{array}$ & $\begin{array}{l}\text { Weight } \\
\text { (kg) }\end{array}$ & $\begin{array}{c}\text { SBP } \\
(\mathrm{mmHg})\end{array}$ & $\begin{array}{c}\mathrm{DBP} \\
(\mathrm{mmHg})\end{array}$ & $\underset{\substack{\mathrm{K} \text { day }) \\
\text { (mmole }}}{\mathrm{K}}$ & $\begin{array}{c}\mathrm{Na} \\
\underset{\text { / day })}{\text { mmole }}\end{array}$ & $\begin{array}{l}\mathrm{Na} / \mathrm{K} \\
\text { (mole } \\
\text { /mole) }\end{array}$ \\
\hline \multirow{6}{*}{ Japan } & Total & 7441 & $\begin{array}{l}150.2 \\
(5.6)\end{array}$ & $\begin{array}{l}52.3 \\
(7.8)\end{array}$ & $\begin{array}{l}129.4 \\
(20.0)\end{array}$ & $\begin{array}{c}77.6 \\
(11.6)\end{array}$ & $\begin{array}{c}56.2 \\
(12.0)\end{array}$ & $\begin{array}{l}161.9 \\
(45.9)\end{array}$ & $\begin{array}{c}3.92 \\
(2.24)\end{array}$ \\
\hline & $40-49$ & 2345 & $\begin{array}{l}152.6 \\
(5.2)\end{array}$ & $\begin{array}{l}53.2 \\
(7.3)\end{array}$ & $\begin{array}{c}122.0 \\
(17.1)\end{array}$ & $\begin{array}{c}74.9 \\
(11.3)\end{array}$ & $\begin{array}{c}54.3 \\
(11.1)\end{array}$ & $\begin{array}{c}168.2 \\
(46.9)\end{array}$ & $\begin{array}{c}4.23 \\
(2.39)\end{array}$ \\
\hline & $50-59$ & 2892 & $\begin{array}{l}150.3 \\
(5.1)\end{array}$ & $\begin{array}{l}52.8 \\
(7.7)\end{array}$ & $\begin{array}{l}130.3 \\
(19.9)\end{array}$ & $\begin{array}{c}78.9 \\
(11.7)\end{array}$ & $\begin{array}{c}56.7 \\
(12.2)\end{array}$ & $\begin{array}{l}162.5 \\
(46.3)\end{array}$ & $\begin{array}{c}3.86 \\
(2.18)\end{array}$ \\
\hline & $60-69$ & 2204 & $\begin{array}{l}147.7 \\
(5.6)\end{array}$ & $\begin{array}{l}50.5 \\
(8.1)\end{array}$ & $\begin{array}{l}136.3 \\
(20.4)\end{array}$ & $\begin{array}{c}78.8 \\
(11.2)\end{array}$ & $\begin{array}{c}57.6 \\
(12.4)\end{array}$ & $\begin{array}{l}154.5 \\
(43.3)\end{array}$ & $\begin{array}{c}3.68 \\
(2.12)\end{array}$ \\
\hline & F-val & & $488 \dagger \dagger$ & $82 \dagger \dagger$ & $319 \dagger \dagger$ & $96 \dagger \dagger$ & $47 \dagger \dagger$ & $51+\dagger$ & $36 \dagger \dagger$ \\
\hline & & & $* *$ & $* *$ & $* *$ & $*$ & n.s. & $*$ & $* *$ \\
\hline \multirow{5}{*}{ Urban } & Total & 3933 & $\begin{array}{l}151.0 \\
(5.6)\end{array}$ & $\begin{array}{l}52.5 \\
(7.7)\end{array}$ & $\begin{array}{l}128.6 \\
(19.6)\end{array}$ & $\begin{array}{c}77.3 \\
(11.5)\end{array}$ & $\begin{array}{c}56.4 \\
(11.7)\end{array}$ & $\begin{array}{l}160.9 \\
(44.8)\end{array}$ & $\begin{array}{c}3.75 \\
(2.11)\end{array}$ \\
\hline & $40-49$ & 1358 & $\begin{array}{l}153.0 \\
(5.1)\end{array}$ & $\begin{array}{l}53.3 \\
(7.3)\end{array}$ & $\begin{array}{c}121.8 \\
(17.0)\end{array}$ & $\begin{array}{c}74.9 \\
(11.6)\end{array}$ & $\begin{array}{c}54.6 \\
(10.8)\end{array}$ & $\begin{array}{l}167.0 \\
(45.4)\end{array}$ & $\begin{array}{c}4.04 \\
(2.25)\end{array}$ \\
\hline & $50-59$ & 1469 & $\begin{array}{l}150.9 \\
(5.1)\end{array}$ & $\begin{array}{l}53.3 \\
(7.7)\end{array}$ & $\begin{array}{l}130.0 \\
(19.2)\end{array}$ & $\begin{array}{c}78.8 \\
(11.3)\end{array}$ & $\begin{array}{c}57.2 \\
(11.9)\end{array}$ & $\begin{array}{l}162.0 \\
(45.2)\end{array}$ & $\begin{array}{c}3.67 \\
(2.04)\end{array}$ \\
\hline & $60-69$ & 1106 & $\begin{array}{l}148.4 \\
(5.7)\end{array}$ & $\begin{array}{c}50.4 \\
(7.9)\end{array}$ & $\begin{array}{l}135.2 \\
(20.5)\end{array}$ & $\begin{array}{c}78.2 \\
(11.3)\end{array}$ & $\begin{array}{c}57.6 \\
(12.2)\end{array}$ & $\begin{array}{l}152.0 \\
(42.2)\end{array}$ & $\begin{array}{c}3.49 \\
(1.96)\end{array}$ \\
\hline & F-val & & $231+\dagger$ & $57+\dagger$ & $160 \dagger \dagger$ & $46 \dagger \dagger$ & $25+\dagger$ & $35+\dagger$ & $22 \dagger \dagger$ \\
\hline \multirow{5}{*}{ Rural } & Total & 3508 & $\begin{array}{l}149.5 \\
(5.5)\end{array}$ & $\begin{array}{l}52.0 \\
(7.8)\end{array}$ & $\begin{array}{l}130.4 \\
(20.5)\end{array}$ & $\begin{array}{c}77.9 \\
(11.6)\end{array}$ & $\begin{array}{c}55.9 \\
(12.4)\end{array}$ & $\begin{array}{c}163.1 \\
(47.1)\end{array}$ & $\begin{array}{c}4.12 \\
(2.37)\end{array}$ \\
\hline & $40-49$ & 987 & $\begin{array}{l}152.0 \\
(5.2)\end{array}$ & $\begin{array}{c}53.1 \\
(7.3)\end{array}$ & $\begin{array}{l}122.2 \\
(17.3)\end{array}$ & $\begin{array}{c}75.0 \\
(10.9)\end{array}$ & $\begin{array}{c}53.9 \\
(11.4)\end{array}$ & $\begin{array}{l}169.8 \\
(48.8)\end{array}$ & $\begin{array}{c}4.48 \\
(2.55)\end{array}$ \\
\hline & $50-59$ & 1423 & $\begin{array}{l}149.6 \\
(5.0)\end{array}$ & $\begin{array}{c}52.4 \\
(7.6)\end{array}$ & $\begin{array}{l}130.7 \\
(20.6)\end{array}$ & $\begin{array}{c}79.0 \\
(12.0)\end{array}$ & $\begin{array}{c}56.1 \\
(12.6)\end{array}$ & $\begin{array}{c}163.1 \\
(47.4)\end{array}$ & $\begin{array}{c}4.06 \\
(2.30)\end{array}$ \\
\hline & $60-69$ & 1098 & $\begin{array}{l}147.0 \\
(5.3)\end{array}$ & $\begin{array}{l}50.5 \\
(8.2)\end{array}$ & $\begin{array}{l}137.4 \\
(20.3)\end{array}$ & $\begin{array}{c}79.3 \\
(11.2)\end{array}$ & $\begin{array}{c}57.6 \\
(12.6)\end{array}$ & $\begin{array}{l}157.0 \\
(44.3)\end{array}$ & $\begin{array}{c}3.88 \\
(2.25)\end{array}$ \\
\hline & F-val & & $245+\dagger$ & $32 \dagger \dagger$ & $156 \dagger \dagger$ & $46 \dagger \dagger$ & $23+\dagger$ & $19 \dagger \dagger$ & $17+\dagger$ \\
\hline
\end{tabular}

Standard deviations in parentheses; SBP, systolic blood pressure; DBP, diastolic blood pressure ; K, estimated one day's urinary potassium excretion by the equation of Hirata et al. $(1985)$ for female $[\mathrm{K}(\mathrm{mmole} / \mathrm{day})=(\mathrm{UK} / \mathrm{UCr} \times 4.21 \times 0.409+1.117) \times$ 25.6; UK, potassium concentration (mEq/liter) in spot urine from 9 to 12 a.m. ; UCr, creatinine concentration $(\mathrm{mg} / 100 \mathrm{ml})$ in spot urine from 9 to 12 a.m.] ; Na, estimated one day's urinary sodium excretion by the equation of Kawasaki et al. (1985) for female $[\mathrm{Na} \quad(\mathrm{mmole} /$ day $)=0.78$ (a.m.) or 0.81 (p.m.) $\times \mathrm{FNa} / \mathrm{FCr} \times 0.541$ (a.m.) or 0.583 (p.m.) $\times$ predicted $\mathrm{Cr}+84$ (a.m.) or 64 (p.m.) ; a.m., for the fractional urine from 8 to 12 a.m.; p.m., for the fractional urine from 12 to 4 p.m.; $\mathrm{FNa}$, sodium concentration $(\mathrm{mEq} / \mathrm{liter})$ in fractional urine; FCr. creatinine concentration $(\mathrm{mg} / \mathrm{liter})$ in fractional urine; predicted $\mathrm{Cr}=8.58 \times$ weight $+5.09 \times$ height $-4.72 \times$ age -74.9$] ;{ }^{*} p<0.05$, ${ }^{* *} p<0.01$, n.s. $p>0.05$, significance of the difference between urban and rural areas.

$\dagger \dagger p<0.01$, significance of the difference among the means of 10-year age groupings (analysis of variance for Japan, urban and rural separately). 
pling of spot urine for sodium and potassium measurements. The subject was seated and has been at rest for at least $5 \mathrm{~min}$. Diastolic blood pressure was taken at the point where the Korotkoff sound disappeared (phase 5).

In order to determine the independent contribution of variables to blood pressure, stepwise multiple regression analyses were run with systolic and diastolic blood pressure as dependent variables, and age, height, weight, sodium and potassium excretion as independent variables. The analyses were done in a backward stepwise method, eliminating at each step the least significant variable until all remaining independent variables were significant at $p<0.05$ levels.

\section{RESUlts}

Seven thousand five hundred and seven females were sampled from 169 municipalities (88 urban and 81 rural) covering all the prefectures in Japan. Spot urine was obtained from 8 a.m. to 12 a.m. in $70(41 \%)$ municipalities, from 12 a.m. to 4 p.m. in $49(29 \%)$ municipalities and from 8 a.m. to 4 p.m. in $50(30 \%)$ municipalities. From these subjects, complete data of 7441 subjects including all the testing variables were used for the analyses. Anthropometric data, blood pressure, estimated one day's urinary potassium and sodium excretions and sodium/potassium ratio in spot urine for the whole country of Japan as well as for urban and rural are presented in Table 1. Blood pressure, sodium excretion and sodium/potassium ratio were higher in rural than in urban. Conversely, height and weight were higher in urban than in rural. Potassium excretion was not different in both areas. Significant differences among means of 10-year age groupings were seen in all veriables.

Product moment correlation coefficients between anthropometric data, blood pressure and urinary cation values in Japan are given in Table 2. Systolic and diastolic blood pressure were positively related to age, weight, sodium and sodium/potassium ratios, and negatively related to height and potassium.

The independent influence of one day's urinary sodium and potassium excre-

TABLE 2. Product moment correlation coefficients between anthropometric data, blood pressure and urinary cation values in Japan $(n=7441)$

\begin{tabular}{lrccccccc}
\hline & Age & Height & Weight & SBP & DBP & $\mathrm{K}$ & $\mathrm{Na}$ & $\mathrm{Na} / \mathrm{K}$ \\
\hline Age & - & & & & & & & \\
Height & $-0.375^{* *}$ & - & & & & & \\
Weight & $-0.142^{* *}$ & $0.412^{* *}$ & - & & & & & \\
SBP & $0.304^{* *}$ & $-0.113^{* *}$ & $0.180^{* *}$ & - & & & \\
$\mathrm{DBP}$ & $0.146^{* *}$ & $-0.026^{*}$ & $0.241^{* *}$ & $0.751^{* *}$ & - & & \\
$\mathrm{K}$ & $0.109^{* *}$ & $-0.043^{* *}$ & $-0.027^{*}$ & $-0.047^{* *}$ & $-0.036^{* *}$ & - & & \\
$\mathrm{Na}$ & $-0.117^{* *}$ & $0.070^{* *}$ & $0.173^{* *}$ & $0.058^{* *}$ & $0.062^{* *}$ & $0.370^{* *}$ & - & \\
$\mathrm{Na} / \mathrm{K}$ & $-0.092^{* *}$ & $-0.046^{* *}$ & 0.007 & $0.094^{* *}$ & $0.059^{* *}$ & $-0.384^{* *}$ & $0.571^{* *}$ & - \\
\hline \multicolumn{7}{c}{${ }^{*} p<0.05,{ }^{* *} p<0.01 ; \mathrm{SBP}$, systolic blood pressure ; DBP, diastolic blood pres- } \\
sure.
\end{tabular}


TABLE 3. Multiple regression analysis of systolic and diastolic blood pressure in middle-aged female adults (40-69 years) in the whole of Japan, urban and mural

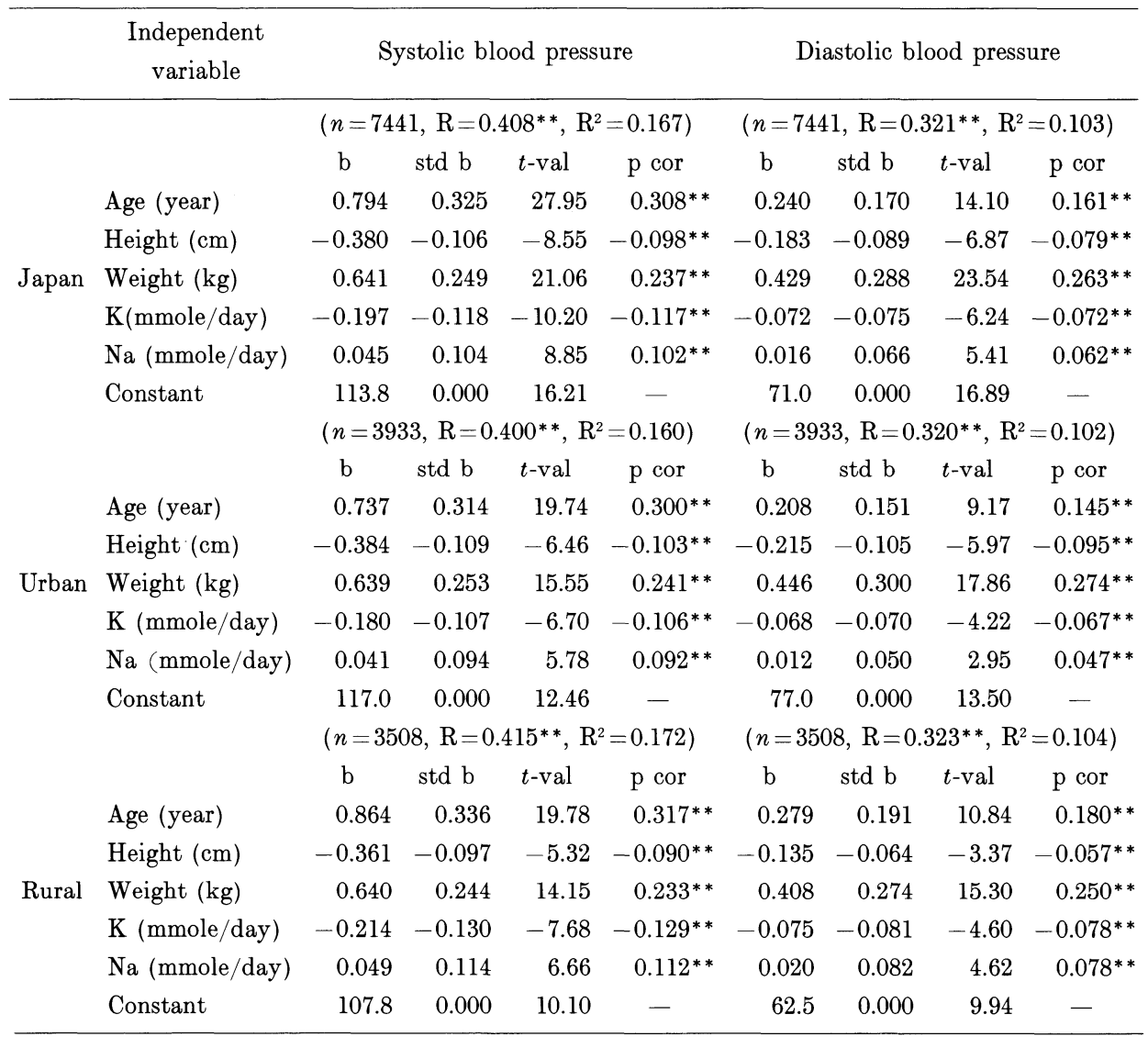

$\mathrm{R}$, multiple correlation coefficient of final model with all factors significant at the $p<0.05$ level ; b, partial regression coefficient; std $\mathrm{b}$, standardized partial regression coefficient; $t$-val, $t$-value of the partial regression coefficient; $\mathrm{p}$ cor, partial correlation coefficient.

${ }^{* *} p<0.01$.

tions on blood pressure was studied by means of stepwise regression analysis. The results are given as partial regression coefficients, corresponding $t$-values and partial correlation coefficients in Tables 3 and 4. Standardized partial regression coefficients are presented to allow for comparisons of relative effects of each independent variable on blood pressure. Final regression models with all significant variables, together with the multiple correlation coefficients are given. Multiple correlation coefficients (R) in the whole of Japan, as well as in urban and rural areas, for systolic and diastolic blood pressure ranged from 0.400 to 0.415 , and from 0.320 to 0.323 , respectively (Table 3 ). In regional observation (Table 4 ), the coefficients varied from 0.264 to 0.503 for systolic, and from 0.246 to 0.423 for diastolic blood pressure. All the coefficients were significant. 
TABLE 4. Multiple regression analysis of systolic and diastolic blood pressure in middle-aged female adults (40-69 years) in 12 regions of Japan

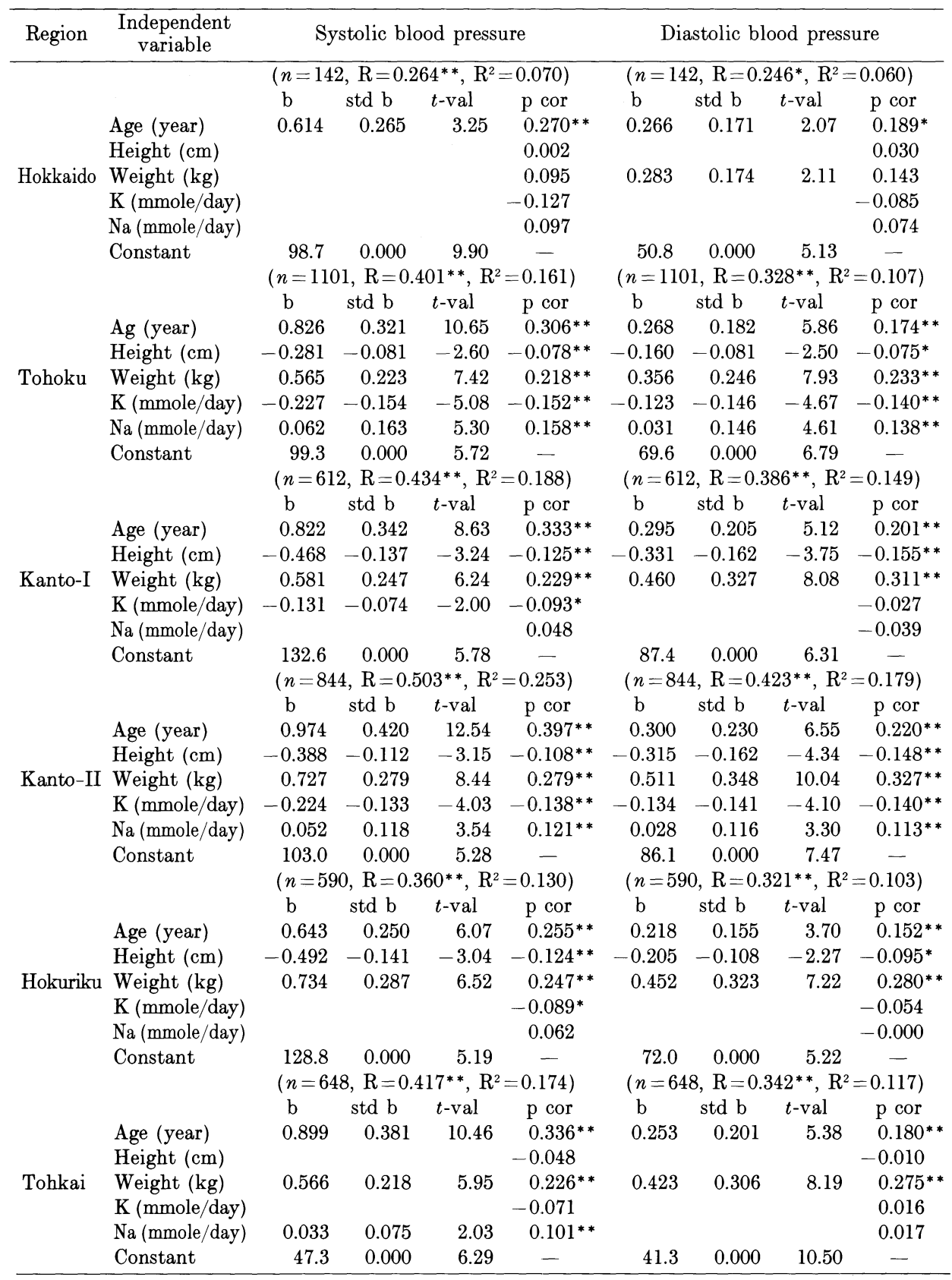


Table 4.

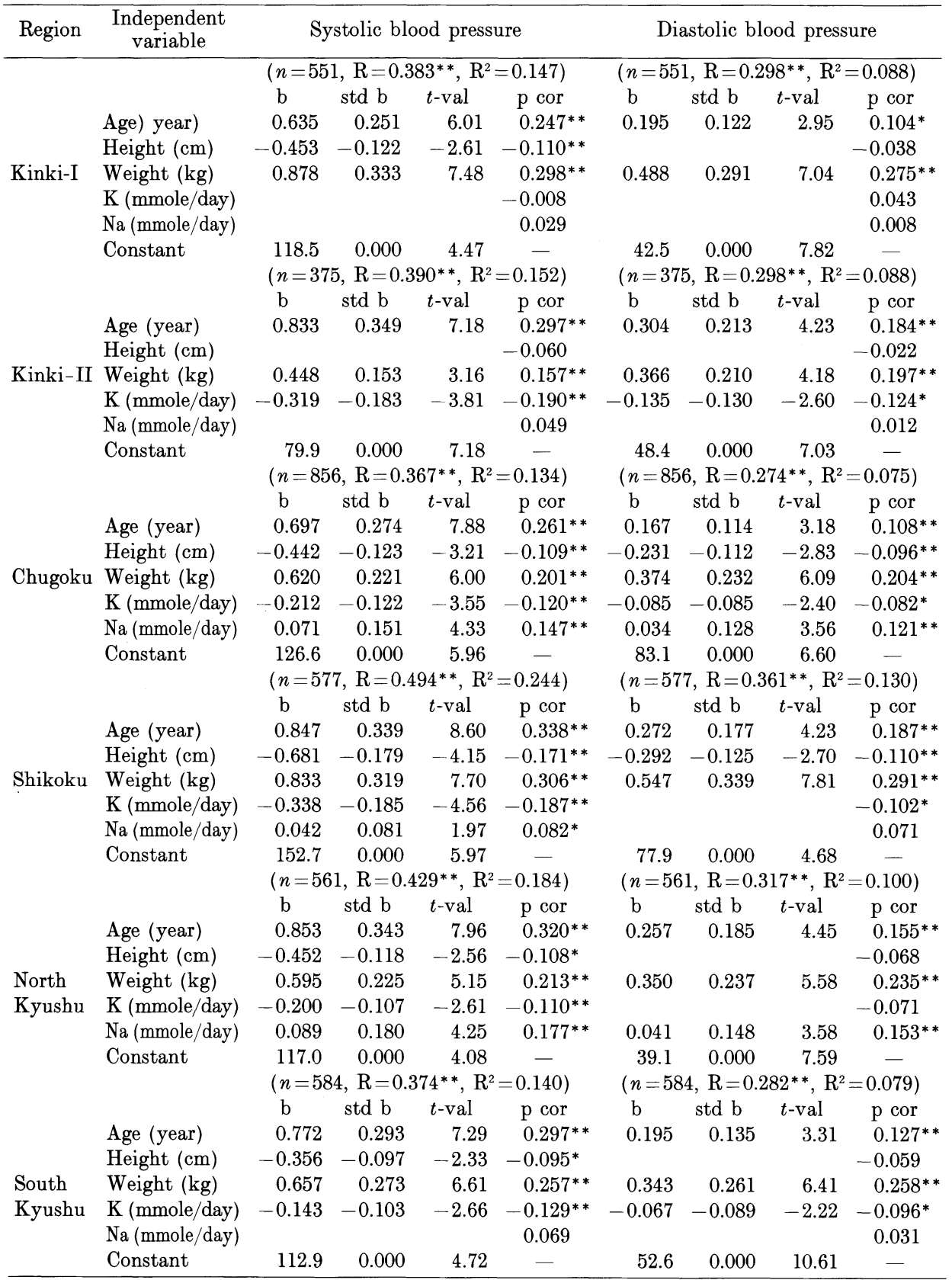

$\mathrm{R}$, multiple correlation coefficient of final model with all factors significant at the $p<0.05$ level ; b, partial regression coefficient; std $\mathrm{b}$, standardized partial regression coefficient; $t$-val, $t$-value of the partial regression coefficient; p cor, partial correlation coefficient.

${ }^{*} p<0.05,{ }^{* *} p<0.01$. 
In most cases, the independent contribution of age and weight to blood pressure consists of a positive relationship, whereas blood pressure is negatively correlated with height. Whenever one day's urinary sodium excretion was independently correlated with blood pressure, the effect was positive, whereas, the effect of one day's potassium excretion on blood pressure was negative. When compared in standardized partial regression coefficients, relative effects of potassium on systolic blood pressure were higher than those of sodium in the whole of Japan, in urban and rural areas, and among five of the twelve regions. Sodium was higher than potassium in only four regions (Tables 3 and 4).

From Tables 3 and 4, it appears that a 100 mmole increase of one day's urinary sodium was associated with an increase in systolic blood pressure by 4.5 , 4.1, 4.9 and 3.3-8.9 $\mathrm{mmHg}$ and with an increase in diastolic blood pressure by 1.6, $1.2,2.0$ and $2.8-4.1 \mathrm{mmHg}$ in the whole of Japan, urban, rural and several regions, respectively. A 100 mmole increase of one day's urinary potassium was associated with a decrease in systolic blood pressure by 19.7, 18.0, 21.4 and 13.1-33.8 $\mathrm{mmHg}$ and with a decrease in diastolic blood pressure by $7.2,6.8,7.5$ and $6.7-13.5$ $\mathrm{mmHg}$ in the whole of Japan, urban, rural and several regions, respectively. Per millimole, potassium was associated more strongly with blood pressure than sodium. The ratio of effectiveness in influencing blood pressure between sodium and potassium was 2.2 to 8.0 for systolic blood pressure, and 2.5 to 5.7 for diastolic blood pressure.

\section{Discussion}

Twenty-four hour urine sampling has been recommended to estimate daily dietary sodium intake. Since it is difficult for individuals to collect 24 -hr urine without disturbing their usual activity, simplified methods for estimating 24-hr urinary sodium and potassium excretions were studied by Kawasaki et al. (1985, 1986), and Hirata et al. (1985), respectively. The former used a $\mathrm{Na} / \mathrm{Cr}$ ratio in 4-hr fractional urine from 8 to 12 a.m. or from 12 to 4 p.m., the latter used a K/ Cr ratio in a morning spot urine from 9 to 12 a.m.

In 1980, we devised the filter paper method (Takemori 1980) for collecting and transporting urine samples in epidemiological studies. Fundamental studies on this method confirmed that sodium, potassium and creatinine levels remained constant for samples absorbed in filter paper strips after storage for several months when the strips were air-dried at room temperature (percentages of sodium, potassium and creatinine concentrations at 54 weeks to the initial levels were $102 \pm 1.8 \%, 98 \pm 2.8 \%, 102 \pm 6.2 \%$ (mean \pm S.D.), respectively) (Takemori 1983). They were extracted almost perfectly into blank solution for flame photometry (Recovery of sodium, potassium and creatinine ranged from 100 to $107 \%$, from 100 to $106 \%$, from 98 to $102 \%$, respectively) (Takemori 1981). This method enables the sampling of urine from a large population and the return of samples from distant places by mail. 
In the present study, we collected spot urine by the filter paper method from middle-aged women who participated in a general health examination conducted by 169 municipalities covering all the prefectures in Japan. Twenty-four-hour sodium and potassium excretions were estimated from the concentrations of sodium, potassium and creatinine in the spot urine at morning or afternoon by the predictive equations of Kawasaki et al. (1985, 1986) and Hirata et al. (1985). This spot urine was approximately equal to the 4-hr fractional urine, and spot urine in the afternoon was also approximately equal to the spot urine in the morning (Takemori et al. 1988). Spot urine was collected during March through December when the general health examinations were performed by the municipalities. Since substantial loss of sweat may reduce the proportion of sodium excreted in urine, a hot season is not suitable to collect a 24 -hr urine sample. The influence of sweating on the ratios of $\mathrm{Na} / \mathrm{Cr}$ and $\mathrm{K} / \mathrm{Cr}$ in spot urine, however, is not clear. Only female participants were used in this study because the health examinations do not consistently include all males, especially in urban areas. This exclusion of male allowed us to avoid the influence of sex on $\mathrm{Na} / \mathrm{Cr}$ and $\mathrm{K}$ / $\mathrm{Cr}$ ratios. This may also avoid the influence of alcohol intake on blood pressure, because only 3 percent of middle-aged women drink alcoholic beverages every day, compared with $47 \%$ of males in Japan (Ministry of Health and Welfare 1983).

Epidemiological evidence has shown that blood pressure increases with age in societies where salt is add to food. In populations with a very low sodium intake, however, blood pressure does not increase with age (MacGregor 1985). The present study confirmed the age-related increases in systolic and diastolic blood pressure. This is consistent with the results of the National Nutrition Survey in Japan (Ministry of Health and Welfare 1988). Differences in blood pressure within urban and rural areas probably indicate that a delay exist in the decrease in blood pressure in rural areas.

In Japan, salt intake of more than $20 \mathrm{~g} /$ day (340 mmole/day) has been reported (Sasaki 1962). Recent data indicate a range from $10.8 \mathrm{~g}$ ( $185 \mathrm{mmole}$ ) to $14.0 \mathrm{~g}$ (239 mmole) by the National Nutrition Survey of Japan in 1986 (Ministry of Health and Welfare 1988). This was obtained by weighing all foodstuffs prior to cooking (weighing method). Estimated sodium excretion of $161.9 \mathrm{mmole} /$ day for Japan in the present study is lower than those in Korea (Kesteloot et al. 1980), Japan (Ikeda et al. 1986), Finland (Karvonen and Punsar 1977), Heidelberg (Schlierf et al. 1980), China (Kesteloot et al. 1987), and Japan in the Intersalt study (1988), and is higher than those in the U.S.A. (Watson et al. 1980; McCarron et al. 1984 ; Gruchow et al. 1985), Belgium (Staessen et al. 1981), and the Netherlands (Kok et al. 1986). Potassium of $56.2 \mathrm{mmole} /$ day in the present study is comparatively lower than in the Netherlands (Kok et al. 1986) and Japan (Ikeda et al. 1986), higher than in China (Kesteloot et al. 1987) and Japan in the Intersalt study (1988), and is close to Korea (Kesteloot et al. 1980) and western 
countries (Staessen et al. 1981 ; McCarron et al. 1984 ; Gruchow et al. 1985).

Population comparison studies have shown a linear correlation between average sodium intake and either average blood pressure (Gleibermann 1973; Simpson 1985) or the prevalence of hypertension (Dahl 1960). Correlation of individual blood pressure with urinary sodium excretion within population has been difficult to demonstrate (Simpson 1985). Most investigations that failed to detect a significant correlation between blood pressure and urinary sodium excretion have attributed this to the difficulty of estimating dietary sodium intake and to individual variability under both parameters (Schlierf et al. 1980; Staessen et al. 1981). In the present study, however, consistent positive correlations between individual urinary sodium and blood pressure were observed in the whole country of Japan, in both urban and rural areas, and also in six of twelve regions in Japan.

In western countries, up to fourteen 24-hr urine samples are required for a correct estimate of sodium intake (Liu et al. 1979). In Oriental populations, however, because of a more standardized diet, only three 24-hr urine samples are necessary (Hsiao et al. 1986). We obtained only one estimated 24-hr urinary sodium and one blood pressure measurement. Subjects receiving medication for hypertension and who also intentionally decreased their sodium consumption may have been included in the present study because such information was not included in the collective schedule. We considered that such a great variation in sodium excretion (about $28 \%$ of coefficient of variation) and a large sample size (over 370 except Hokkaido region) established a relationship between sodium and blood pressure even under conditions mentioned above.

Consistent negative relationships between blood pressure and potassium excretion were observed in the present study. These findings are compatible with the studies of Dahl et al. (1972) showing that potassium protected against the rising effect of sodium on blood pressure in rats. Some recent epidemiological studies have demonstrated this negative relationship between blood pressure and urinary potassium excretion (Walker et al. 1979; Kesteloot et al. 1980, 1987 ; Watson et al. 1980; Staessen et al. 1981; Khaw and Barrett-Connor 1984; Gruchow et al. 1985). A prospective population study has shown that a 10mmole increase in daily potassium intake was associated with a $40 \%$ reduction in the risk of stroke-related mortality (Khaw and Barrett-Connor 1987). These findings support the hypothesis that a high intake of potassium may protect against the effect of sodium on raising blood pressure and against stroke-related death.

The independent contribution of sodium to blood pressure is small. A 100 mmole increase of one day's urinary sodium was associated with an increase in systolic blood pressure by $4.5 \mathrm{mmHg}$ and in diastolic blood pressure by $1.6 \mathrm{mmHg}$ in the Japanese population. These slopes correspond approximately to those found in Korea (Kesteloot et al. 1980), China (Kesteloot et al. 1987), American children (Cooper et al. 1980) and in the Intersalt study (1988), but they are less 
steep than those found by Gleibermann $(1973) ; 1.35 \mathrm{mmHg} / \mathrm{g}$ salt $(7.9 \mathrm{mmHg} /$ $100 \mathrm{mmole} \mathrm{Na}$ ) for systolic blood pressure and $0.79 \mathrm{mmHg} / \mathrm{g}$ salt $(4.6 \mathrm{mmHg} / 100$ mmole $\mathrm{Na}$ ) for diastolic blood pressure in females. These slopes are the best available estimates of the strength of association to be expected within a simple population (Watt and Foy 1982). Some reasons for this small association may be as follows: (1) The within individual variability of both sodium and blood pressure is large. (2) It appears possible that at sodium intakes of 120-200 mmole the slope of the regression line is less steep (Simpson 1985). (3) If only certain individuals were susceptible to the effect of dietary sodium, the observed association with blood pressure would be diluted by inclusion of many non-susceptible individuals (Watt and Foy 1982).

An increase in intake of 100 mmole potassium would result in a decrease in systolic blood pressure by $19.7 \mathrm{mmHg}$ and in diastolic blood pressure by 7.2 $\mathrm{mmHg}$ in the Japanese population. The lowering effect of potassium per mmole is higher than the increasing effect of sodium. This finding is in agreement with the results obtained in Korea (Kesteloot et al. 1980), China (Kesteloot et al. 1987) and the Intersalt study (1988). This may be partially attributed to a smaller variation in the daily intake of potassium within individual persons compared to sodium (Khaw and Barrett-Connor 1984).

The use of the sodium/potassium ratio seems logical, as the opposite effect of sodium and potassium on blood pressure have been observed in the present study and others (Kesteloot et al. 1980, 1987; Gruchow et al. 1985). In the present investigation, sodium and potassium were, however, separately entered in regression analysis as independent variables in order to determine the independent effect of each ion on blood pressure.

Coefficients of determination $\left(\mathrm{R}^{2}\right)$ of 0.167 for systolic and 0.103 for diastolic blood pressure in this study (Table 3 ) indicate that independent variables together only account for 16.7 and $10.3 \%$ of the total observed variation of the systolic and diastolic blood pressure, respectively. Other factors such as genetics, other nutrients, physical exercise and psycho-social stress could be important in determining the blood pressure of individuals within a population.

In conclusion, the results of these analyses confirm that in a comparison of individual blood pressure with urinary sodium or potassium excretion, sodium excretion consistently correlated positively and potassium excretion negatively with blood pressure.

\section{References}

1) Cooper, R., Soltero, I., Liu, K., Berkson, D., Levinson, S. \& Stamler, J. (1980) The association between urinary sodium excretion and blood pressure in children. Circulation, 62, 97-104.

2) Dahl, L.K. (1960) Possible role of salt intake in the development of essential hypertension. In: Essential Hypertension, edited by K.D. Bock \& P.T. Cottier, Springer-Verlag, Berlin-Gottingen-Heidelberg, pp. 53-65. 
3) Dahl, L.K., Leitl, G. \& Heine, M. (1972) Influence of dietary potassium and sodium/ potassium molar ratios on the development of salt hypertension. J. Exp. Med., 136, 318-330.

4) Gleibermann, L. (1973) Blood pressure and dietary salt in human populations. Ecol. Food Nutr., 2, 143-156.

5) Gruchow, H.W., Sobocinski, K.A. \& Barboriak. J.J. (1985) Alcohol, nutrient intake, and hypertension in US abults. JAMA, 253, 1567-1570.

6) Hirata, K., Fushimi, T., Ishii, H., Hayashi, I., Hanaoka, H., Mizunuma, S., Morimoto, S. \& Toda, M. (1985) A method of estimating urinary potassium excretion by morning spot urine sampling, at the 39th annual meeting of Japanese Society of Nutrition and Food Sciences, Tokyo, April, p. 129. (Japanese)

7) Hsiao, Z.K., Wang, S.Y., Hong, Z.G., Liu, K., Cheng, T.Y., Stamler, J. \& Tao, S.C. (1986) Timed overnight sodium and potassium excretion and blood pressure in steel workers in North China. J. Hypertens., 4, 345-350.

8) Iimura, O., Kijima, T., Kikuchi, K., Miyama, A., Ando, T., Nakao, T. \& Takigami, Y. (1981) Studies on the hypotensive effect of high potassium intake in patients with essential hypertension. Clin. Sci., 61, 77s-80s.

9) Ikeda, M., Kasahara, M., Koizumi, A. \& Watanabe, T. (1986) Correlation of cerebrovascular disease standardized mortality ratios with dietary sodium and the sodium/potassium ratio among the Japanese population. Prev. Med., 15, 46-59.

10) Intersalt Cooperative Research Group (1988) Intersalt: An international study of electrolyte excretion and blood pressure. Results for 24 hour urinary sodium and potassium excretion. Br. Med. J., 297, 319-328.

11) Karvonen, M.J. \& Punsar, S. (1977) Sodium excretion and blood pressure of west and east Finns. Acta Med. Scand., 202, 501-507.

12) Kawasaki, T., Uezono, K. \& Kikkawa, K. (1985) Studies on estimation of 24-hour urinary sodium excretion from predicted creatinine excretion and fractional urine sodium/creatinine ratio. Jpn. J. Hypertension, 8, 42. (Japanese)

13) Kawasaki, T., Uezono, K., Utsunomiya, H., Imamura, K., Kikkawa, K., Ueno, M. \& Fujishima, M. (1986) Studies on estimation of 24-hour urinary sodium excretion from predicted creatinine excretion and fractional urine sodium/creatinine ratio. $J$. Health Sci, 8, 57-63. (in Japanese with English summary)

14) Kesteloot, H., Park, B.C., Lee, C.S., Brems-Heyns, E. \& Joossens, J.V. (1980) A comparative study of blood pressure and sodium intake in Belgium and in Korea. In : Epidemiology of Arterial Blood Pressure, edited by H. Kesteloot \& J.V. Joossens, Martinus Nijhoff publishers, Hague-Boston-London, pp. 453-470.

15) Kesteloot, H., Huang, D.X., Li, Y.L., Geboers, J. \& Joossens, J.V. (1987) The relationship between cations and blood pressure in the People's Republic of China. Hypertension, 9, 654-659.

16) Khaw, K.T. \& Thom, S. (1982) Randomised double-blind cross-over trial of potassium on blood-pressure in normal subjects. Lancet, 2, 1127-1129.

17) Khaw, K.T. \& Barrett-Connor, E. (1984) Dietary potassium and blood pressure in a population. Am. J. Clin. Nutr., 39, 963-968.

18) Khaw, K.T. \& Barrett-Connor, E. (1987) Dietary potassium and stroke-associated mortality. A 12-year prospective population study. N. Engl. J. Med., 316, 235240.

19) Kok, F.J., Vandenbroucke, J.P., van der Heide-Wessel, C. \& van der Heide, R.M. (1986) Dietary sodium, calcium, and potassium, and blood pressure. Am. J. Epidemiol., 123, 1043-1048.

20) Liu, K., Cooper, R., McKeever, J., McKeever, P., Byington, R., Soltero, I., Stamler, R., Gosch, F., Stevens, E. \& Stamler. J. (1979) Assessment of the association between habitual salt intake and high blood pressure: Methodological problems. Am. J. Epidemiol., 110, 219-226. 
21) MacGregor, G.A. (1985) Sodium is more important than calcium in essential hypertension. Hypertension, 7, 628-637.

22) MacGregor, G.A., Smith. S.J., Markandu, N.D., Banks, R.A. \& Sagnella, G.A. (1982) Moderate potassium supplementation in essential hypertension. Lancet, 2, 567-570.

23) McCarron, D.A., Morris, C.D., Henry, H.J. \& Stanton, J.L. (1984) Blood pressure and nutrient intake in the United States. Science, 224, 1392-1398.

24) Ministry of Health and Welfare, Government of Japan (eds.) (1983) National Survey on Circulatory Disorders 1980. Japanese Heart Association, Tokyo, p. 131. (Japanese)

25) Ministry of Health and Welfare, Government of Japan (eds.) (1988) Nutrition Status in Japan-Report of 1986 National Nutrition Survey. Dai-ichi Shuppan, Tokyo. (Japanese)

26) Sasaki, N. (1962) High blood pressure and the salt intake of the Japanese. Jpn. Heart J., 3, 313-324.

27) Schlierf, G., Arab, L., Schellenberg, B., Oster, P., Mordasini, R., Schmidt-Gayk, H. \& Vogel, G. (1980) Salt and hypertension: Data from the "Heidelberg Study". Am. J. Clin. Nutr., 33, 872-875.

28) Simpson, F.O. (1985) Blood pressure and sodium intake. In: Handbook of Hypertension, vol. 6: Epidemiology of Hypertension, edited by C.J. Bulpitt, Elsevier, Amsterdam, New York, Oxford, pp. 175-190.

29) Staessen, J., Fagard, R., Lijnen, P. \& Amery, A. (1981) Salt and blood pressure in Belgium. J. Epidemiol. Community Health, 35, 256-261.

30) Takemori, K. (1980) Collection and transport of urine samples by filter paper absorption method. The method of the determination of sodium, potassium and creatinine concentration in urine. Jpn. J. Hyg., 35, 721-727. (in Japanese with English summary)

31) Takemori, K. (1981) Recovery of sodium, potassium and creatinine by filter paper method. In case of flame spectrophotometry by internal standardization technique. Hirosaki Med. J., 33, 549-551. (in Japanese with English summary)

32) Takemori, K. (1983) Long term preservation of urine sodium, potassium and creatinine by filter paper method. Hirosaki Med. J., 35, 341-344. (in Japanese with English summary)

33) Takemori, K., Mikami, S., Nihira, S. \& Sasaki, N. (1988) A comparison between estimations of 24-hour urinary sodium and potassium excretion. Jpn. J. Hyg., 43, 225. (Japanese)

34) The Japanese Association for Cerebro-Cardiovascular Disease Control (eds.) (1983) The diagnostic definition of cerebrovascular diseases. In: The Handbook of Health Guidance to Hypertension and Cerebrovascular Disease, Hokendoujinsha, Tokyo, pp. 114-115. (Japanese)

35) Walker, W.G., Whelton, P.K., Saito, H., Russell, R.P. \& Hermann, J. (1979) Relation between blood pressure and renin, renin substrate, angiotensin II, aldosterone and urinary sodium and potassium in 574 ambulatory subjects. Hypertension, 1, 287-291.

36) Watson, R.L., Langford, H.G., Abernethy, J., Barnes, T.Y. \& Watson, M.J. (1980) Urinary electrolytes, body weight, and blood pressure. Hypertension, 2, Suppl. I, I-93-I-98.

37) Watt, G.C.M. \& Foy, C.J.W. (1982) Dietary sodium and arterial pressure : Problems of studies within a single population. J. Epidemiol. Community Health, 36, 197-201. 